\title{
Elastic, Mechanical, and Phonon Behavior of Orpiment Arsenic Trisulfide under Pressure
}

\author{
Liwu Jiang $\mathbb{D}^{1,2}$ Meiling Wu $\mathbb{D},{ }^{3}$ Peng Shi $\mathbb{D},{ }^{1}$ and Chuanhui Zhang $\mathbb{C}^{1}$ \\ ${ }^{1}$ National Center for Materials Service Safety, University of Science and Technology Beijing, Beijing 100083, China \\ ${ }^{2}$ NCS Testing Technology Co. Ltd., Beijing 100081, China \\ ${ }^{3}$ Beijing Institute of Aeronautical Materials, Beijing 100095, China
}

Correspondence should be addressed to Liwu Jiang; lwjiang@ustb.edu.cn

Received 13 August 2020; Revised 20 August 2020; Accepted 8 September 2020; Published 19 September 2020

Academic Editor: Jiangwei LIU

Copyright (c) 2020 Liwu Jiang et al. This is an open access article distributed under the Creative Commons Attribution License, which permits unrestricted use, distribution, and reproduction in any medium, provided the original work is properly cited.

Arsenic trisulfide $\left(\mathrm{As}_{2} \mathrm{~S}_{3}\right)$ has been found to be an excellent glass former at high temperature and pressure. However, there is still some scarcity for the elastic and phonon behavior of the orpiment phase. By using the Dreiding force field of the geometry optimization computations, we investigated the elastic constants, mechanical moduli, and the phonon dispersion of orpiment $\mathrm{As}_{2} \mathrm{~S}_{3}$ under the pressure from 0 to $5 \mathrm{GPa}$. Some results of the elastic parameters of orpiment- $\mathrm{As}_{2} \mathrm{~S}_{3}$ at $0 \mathrm{GPa}$ are consistent with the experimental data. The phonon dispersions for orpiment $\mathrm{As}_{2} \mathrm{~S}_{3}$ under pressure are also reasonable with previous calculations.

\section{Introduction}

The computational simulation of materials has been a successful and rapid tool to understand the complex physical problems of materials. In addition, predicting the good elastic and mechanical properties of materials is a necessary demand for recent solid-state physics and science. And these mechanical properties at high pressure and temperature are also important for the development of modern technologies [1-4].

Arsenic trisulfide $\left(\mathrm{As}_{2} \mathrm{~S}_{3}\right)$ is the most studied compound due to its properties like large glass-forming ability, excellent infrared radiation transmission, and structural and mechanical properties $[5,6]$. Under normal conditions, the stable phase is an orpiment layered structural semiconductor material. In its lattice, each As atom is surrounded by three $S$ atoms, whereas each $S$ atom is surrounded by two As atoms. At normal conditions, no other crystalline metastable phases of $\mathrm{As}_{2} \mathrm{~S}_{3}$ could be artificially synthesized for a long time. The structure properties of arsenic sulfides were studied by the density functional theory [7], tight binding method [8], and nonempirical localized approach method [9]. The density of valence states of crystalline arsenic sulfides was investigated by using X-ray photoemission spectroscopy [10]. The optical and transport properties and electronic structure of Ni-doped arsenic sulfides were also studied [11]. Only one new phase of $\mathrm{As}_{2} \mathrm{~S}_{3}$ named anorpiment has been naturally discovered recently [12]. It has low symmetry with triclinic structure and is made of covalently bonded layers of As and $\mathrm{S}$ atoms with a similar coordination arranged in a different stacking sequence by van der Waals force.

The high-pressure technique implies the active use of pressure as the fundamental thermodynamic variable for innovative material design. M. Güler and E. Güler reported that the classical force field can describe the surface, elastic, and phonon properties of wurtzite $\mathrm{ZnS}$ accurately, and the calculated data were in good agreement with the related experimental results [4]. Another previous work [13] pointed out that bonding disorder can be expected under high pressure in $\mathrm{As}_{2} \mathrm{~S}_{3}$ glass, changing structural, vibrational, and optical properties. For example, using high-precision compressibility measurement and in situ high-energy X-ray diffraction to high pressure, the enhanced refractive index of the recovered $\mathrm{As}_{2} \mathrm{~S}_{3}$ glass is promising for optical applications with improved functionalities [14]. A nearly permanent red shift in optical absorption after decompression can be used in high-impact-force optical sensors. In order to expand its application in the industrial field, it is necessary 
and interesting to study the elastic constants, mechanical moduli, and the phonon dispersion of orpiment $\mathrm{As}_{2} \mathrm{~S}_{3}$ under high pressure.

In this paper, we provided the details of theoretical calculations with the employed interatomic potential in Section 2. Then, we discussed our results with the available experimental results in Section 3. Finally, we presented the main findings in Conclusions.

\section{Computational Methods}

The most significant feature of material modeling is the choice of the interatomic potentials. A proper interatomic potential can describe the physical properties of materials sufficiently and accurately. The empirical potentials are the modelling tools for materials because they can yield reasonable results. These kinds of potentials can provide reasonable results of the structures, energies, and elastic and mechanical properties of alloys $[15,16]$ and many other materials $[17,18]$.

In this work, all the theoretical calculations were carried out with the General Utility Lattice Program (GULP) molecular dynamics code [19]. This versatile code allows the concerned structures to be optimized at constant pressure (all internal and cell variables are included) or at constant volume (unit cell remains frozen). The Dreiding force field [20] was chosen to be the empirical potentials for simulations. It is widely used in research describing the properties of organic and inorganic materials $[21,22]$. To avoid the constraints, constant pressure optimization was applied to the geometry of $\mathrm{o}-\mathrm{As}_{2} \mathrm{~S}_{3}$ cells with the Newton-Raphson method based on the Hessian matrix calculated from the second derivatives. In Figure 1, the cell geometry of $\mathrm{o}-\mathrm{As}_{2} \mathrm{~S}_{3}$ was assigned as $a=10.779 \AA, b=3.304 \AA, c=13.565 \AA$, and $\alpha=$ $\beta=\gamma=90^{\circ}$ with space group PNMA. In the geometry optimization calculations, the Hessian matrix was recursively updated with the BFGS [23] algorithm. The phonon and associated properties of $\mathrm{o}-\mathrm{As}_{2} \mathrm{~S}_{3}$ were also analyzed as a function of pressure within the ranges between $0 \mathrm{GPa}$ and $5 \mathrm{GPa}$ in steps of $1 \mathrm{GPa}$. We captured the phonon density of states and dispersions for a material after specifying a shrinking factor with phonon computations. Furthermore, phonons are described by calculating their values at points in a reciprocal space within the first Brillouin zone of the given crystal. To achieve the Brillouin zone integration and obtain the PDOS, we used a standard and reliable scheme developed by Monkhorst and Pack [24] with $6 \times 6 \times 6 k$-point mesh.

\section{Results and Discussion}

As people know the volume of the crystal materials decreases, the density increases straightly under pressure. The density curve of $\mathrm{o}-\mathrm{As}_{2} \mathrm{~S}_{3}$ under pressure is shown in Figure 2. Under zero temperature, $\mathrm{O}-\mathrm{As}_{2} \mathrm{~S}_{3}$ has the lowest density value of $3.38 \mathrm{~g} / \mathrm{cm}^{3}$ at $0 \mathrm{GPa}$ and has the highest density value of $3.80 \mathrm{~g} / \mathrm{cm}^{3}$ at $5 \mathrm{GPa}$. These results are consistent with the experimental value of $3.49 \mathrm{~g} / \mathrm{cm}^{3}$ [25]. So our prediction crystal structure of $\mathrm{o}-\mathrm{As}_{2} \mathrm{~S}_{3}$ under pressure is accurate.
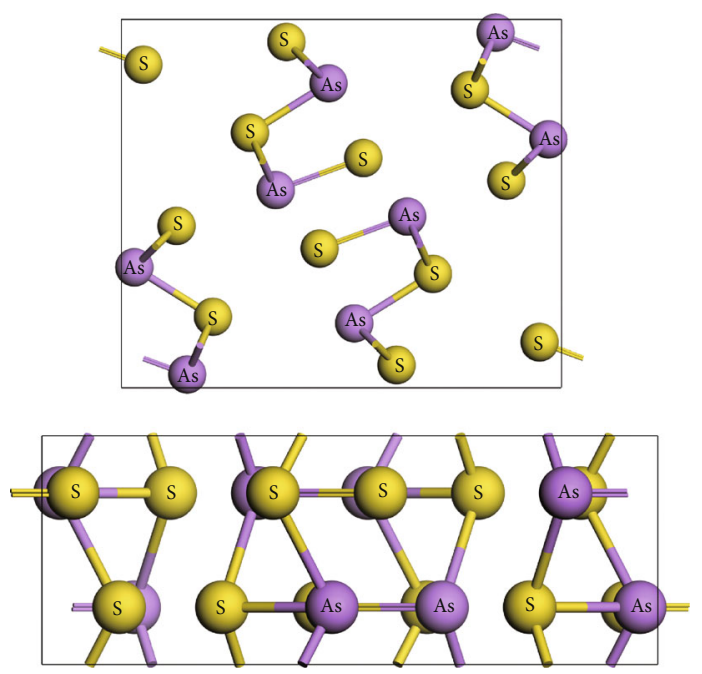

FIgURE 1: The crystal structure of orpiment $\mathrm{As}_{2} \mathrm{~S}_{3}$. The yellow and purple atoms represent the $S$ and As elements, respectively.

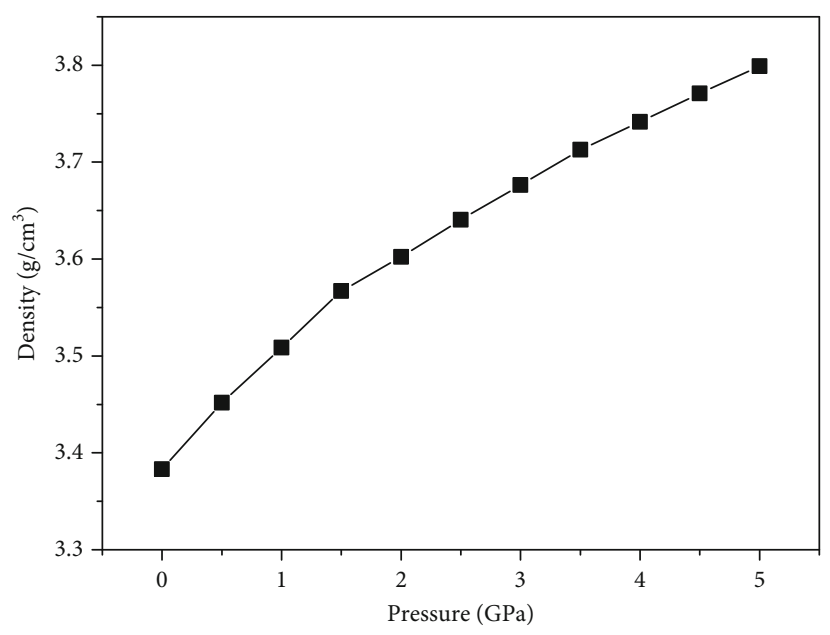

FIgURE 2: The density of orpiment $\mathrm{As}_{2} \mathrm{~S}_{3}$ under pressure.

Then, we continued to compute the elastic and mechanical properties of $\mathrm{o}-\mathrm{As}_{2} \mathrm{~S}_{3}$ under pressure, such as the elastic constants $\left(C_{\mathrm{ij}}\right)$, bulk modulus $(B)$, shear modulus $(G)$ and Young moduli $(E)$, and elastic wave velocities $\left(V_{L}\right.$ and $\left.V_{S}\right)$. The elastic constants were obtained by the second derivatives of the energy density with respect to strain. And the mechanical parameters were obtained by the linear combination of elastic constants using Voigt, Reuss, and Hill (VRH) approximations [26, 27].

Elastic constants deliver clear perceptions about the mechanical and other associated properties of materials. Though the elastic constants we obtained belong to the monocrystalline, these results also have important guiding significance for polycrystalline materials [28, 29]. For orthorhombic crystals, seven well-known elastic constants exist, which are specified as $C_{11}, C_{12}, C_{13}, C_{22}, C_{23}, C_{33}$, and $C_{44}$ [30]. Figure 3 shows the results of $C_{11}, C_{12}, C_{13}, C_{22}, C_{23}$, $C_{33}$, and $C_{44}$ constants for $\mathrm{o}-\mathrm{As}_{2} \mathrm{~S}_{3}$ under pressures between $0 \mathrm{GPa}$ and $5 \mathrm{GPa}$. The calculated elastic constants are in the range of $C_{22}>C_{11}>C_{33}>C_{13}>C_{23}>C_{12}>C_{44}$. The elastic 


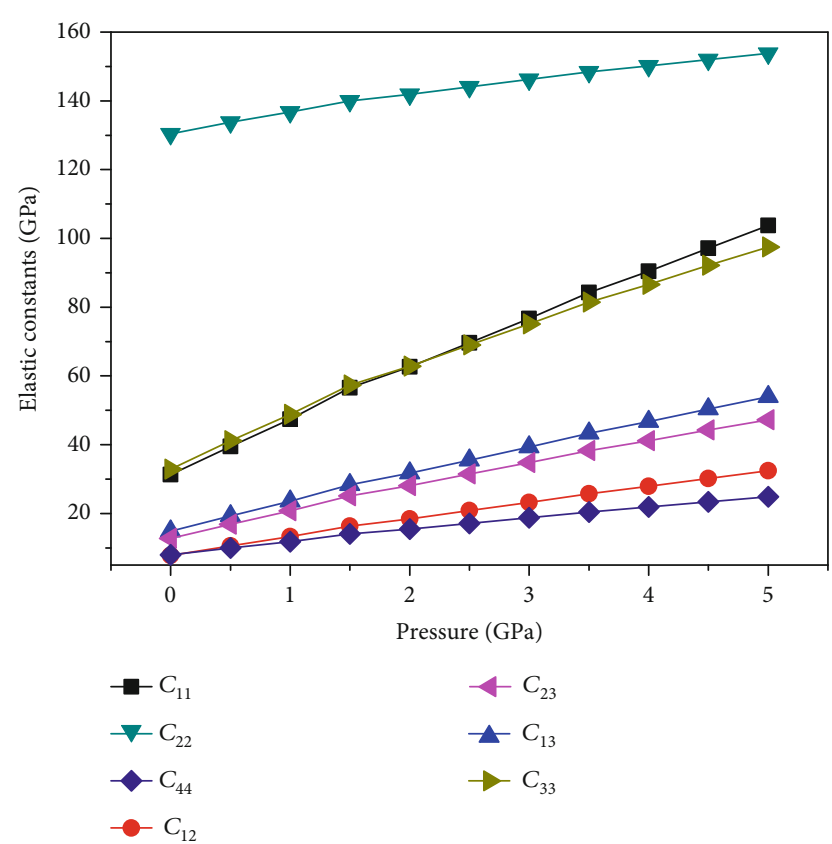

FIgURE 3: The elastic constants of orpiment $\mathrm{As}_{2} \mathrm{~S}_{3}$ under pressure.

constants $C_{11}$ and $C_{33}$ represent the longitudinal elastic character, and they increase under pressure for the reason of elastic wave propagation occurs easily under pressure. The values of $C_{11}$ and $C_{33}$ are similar to each other at $0 \mathrm{GPa}$, and the difference between them exists as the pressure increases. The elastic constant $C_{44}$ represents the shear elastic response to retarded wave propagation, and it also increases with the increasing pressure. In Table 1 , our results for $C_{13}, C_{33}$, and $\mathrm{C}_{44}$ of $\mathrm{o}-\mathrm{As}_{2} \mathrm{~S}_{3}$ at $0 \mathrm{GPa}$ are consistent with the experimental results of $\mathrm{McNeil}$ et al. [31], but $C_{11}$ and $C_{22}$ are larger than the data in Ref. [31]. The reason is due to the anisotropy of $\mathrm{o}-\mathrm{As}_{2} \mathrm{~S}_{3}$ and the measuring technology of Brillouin scattering and the size of samples. McNeil's measurement sample was made a natural crystal from Macedonia, and it was in the form of a thin plate roughly $5 \mathrm{~mm}$ square and $1 \mathrm{~mm}$ thick with only two good-quality surfaces (both perpendicular to the [010] axis). However, we used an orthorhombic crystal cell to do the simulation. So the anisotropy of o- $\mathrm{As}_{2} \mathrm{~S}_{3}$ would influence the results of elastic parameters between us and the McNeil's.

According to stability, the mechanical stability criterion for orthorhombic crystals is $C_{11}>0, C_{44}>0, C_{11}+C_{22}>2$ $C_{12}$, and $C_{11}+C_{22}+C_{33}+2\left(C_{12}+C_{13}+C_{23}\right)>0$ [30]. Our calculated results of elastic constants of o- $\mathrm{As}_{2} \mathrm{~S}_{3}$ obey the mechanical stability criterion, which consequently indicates that the $\mathrm{o}-\mathrm{As}_{2} \mathrm{~S}_{3}$ is mechanically stable in its ground state.

The bulk modulus represents an essential elastic constant connected to the bonding strength and is used as a primary parameter for the calculation of a material's hardness. The shear modulus represents the resistance to reversible deformations upon shear stress, while Young's modulus is defined as the ratio of the tensile stress to the corresponding tensile strain. Figure 4 shows the $B, G$, and $E$ of $\mathrm{o}-\mathrm{As}_{2} \mathrm{~S}_{3}$ under pressure, and they all increase with the increasing pressure. How- ever, the increase of $B$ and $E$ is obviously stronger than that of $G$. This result points that $\mathrm{o}-\mathrm{As}_{2} \mathrm{~S}_{3}$ is an isotropic material, so the external pressure produces a uniform volume compression effect and much less effect on the shear deformation of the material. Usually, brittle materials display a considerable resistance to the deformation before fracture, whereas ductile materials would be deformed easily. Ductility is a mechanical property of the material that represents the ability to plastically deform before it undergoes the fracture. Brittleness refers to the nature of fracture failure of materials without obvious plastic deformation when the external force reaches a certain limit. Ductility and brittleness are important for the production of the desired materials, so we continued to study the ductile and brittle behaviors of $\mathrm{o}-\mathrm{As}_{2} \mathrm{~S}_{3}$ under pressure. The Pugh ratio evaluation $(G / B)$ [32], C for ductile and brittle performances of materials, was considered in this section. A low $G / B$ value is associated with ductility, whereas a higher one corresponds to the brittle nature. The critical value which separates ductile and brittle materials is around 0.5 . Our results show that $G / B$ values decrease from 0.42 $(P=0 \mathrm{GPa})$ to $0.32(P=5 \mathrm{GPa})$ at zero temperature for $\mathrm{O}$ $\mathrm{As}_{2} \mathrm{~S}_{3}$ as inserted in Figure 4. Therefore, $\mathrm{o}-\mathrm{As}_{2} \mathrm{~S}_{3}$ is a kind of a ductile material for the entire pressure range.

It is known that the longitudinal $\left(V_{L}\right)$ and shear elastic $\left(V_{S}\right)$ waves may arise in solids at low temperatures due to vibrational excitations originating from the acoustic modes [33]. And the pressure behavior of the $V_{L}$ and $V_{S}$ of o$\mathrm{As}_{2} \mathrm{~S}_{3}$ pressure at $T=0 \mathrm{~K}$ is shown in Figure 5. The $V_{L}$ indicates the longitudinal elastic wave velocity, and the $V_{S}$ indicates the shear wave velocity. We can see that $V_{L}$ has a significant increment compared to $V_{S}$, and this is the most common case for materials. The reason is that the bulk modulus and Young's modulus compared to the shear modulus have the same trend.

The ground state phonon dispersions of $\mathrm{o}-\mathrm{As}_{2} \mathrm{~S}_{3}$ were analyzed by using Dreiding potential quantitatively and compared in Reference [34] with theoretical results. We calculated the partial ground state phonon density of states (PDOS) of $\mathrm{o}-\mathrm{As}_{2} \mathrm{~S}_{3}$ to explain the contribution of As and $\mathrm{S}$ elements to the total phonon density of state (TDOS) of the material and showed them in Figure 6. The PDOS and TDOS appear with some separated regions corresponding to the longitudinal acoustic mode, transverse acoustic mode, longitudinal optic, and transverse optic mode of o- $\mathrm{As}_{2} \mathrm{~S}_{3}$. Besides, the contribution of the As element to acoustic phonon modes is the same as that of S element, but in the high-frequency area, the case is different, and the contribution of the $S$ element is dominant to optical modes. There is a big gap of $200 \mathrm{~cm}^{-1}$ (between the frequencies $300 \mathrm{~cm}^{-1}$ and $500 \mathrm{~cm}^{-1}$ ) originating from the mass differences of As and $\mathrm{S}$ elements of $\mathrm{O}-\mathrm{As}_{2} \mathrm{~S}_{3}$.

In addition, Figure 7 shows the phonon dispersion of o$\mathrm{As}_{2} \mathrm{~S}_{3}$ along the chosen $\Gamma$-A path (the same as with original Ref [29]) in a reciprocal space for pressures $0 \mathrm{GPa}$ and $5 \mathrm{GPa}$. It is seen that the pressure at $5 \mathrm{GPa}$ shifts the phonon dispersion curves to higher frequency values. The reason is the atoms of $\mathrm{o}-\mathrm{As}_{2} \mathrm{~S}_{3}$ move towards each other and have to locate in the steeper potential wells under high pressures. In Figure 8, the corresponding PDOS curves of five pressures 
TABLE 1: The present calculated results and experimental results of the elastic and mechanical parameters of $\mathrm{As}_{2} \mathrm{~S}_{3}$ at 0 pressure.

\begin{tabular}{lccccccc}
\hline Parameter & $C_{11}(\mathrm{GPa})$ & $C_{12}(\mathrm{GPa})$ & $C_{13}(\mathrm{GPa})$ & $C_{22}(\mathrm{GPa})$ & $C_{23}(\mathrm{GPa})$ & $C_{33}(\mathrm{GPa})$ & $C_{44}(\mathrm{GPa})$ \\
\hline Present & 31.3 & 7.8 & 14.8 & 130.4 & 12.8 & 32.9 & 2.9 \\
EXP. [30] & 99.6 & - & 20.6 & 27.1 & - & 1.1 \\
\hline Parameter & $B(\mathrm{GPa})$ & $G(\mathrm{GPa})$ & $E(\mathrm{GPa})$ & $V_{S}(\mathrm{~km} / \mathrm{s})$ & $V_{L}(\mathrm{~km} / \mathrm{s})$ & & \\
Present & 25.8 & 10.7 & 58.3 & 1.8 & 3.4 & & \\
\hline
\end{tabular}

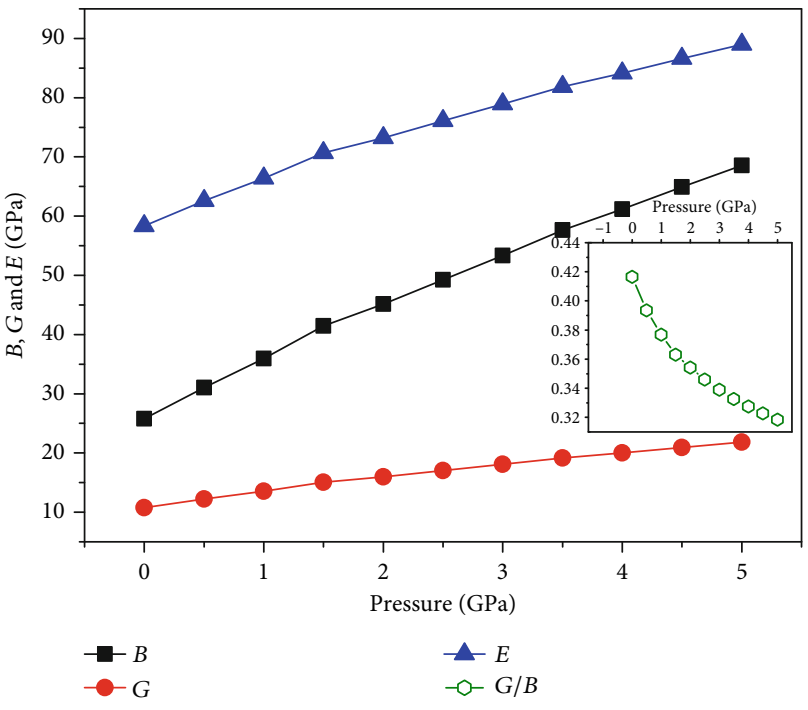

FIgURE 4: The mechanical moduli of orpiment $\mathrm{As}_{2} \mathrm{~S}_{3}$ under pressure. The inserted picture shows the Pugh ratio evaluation $(G / B)$.

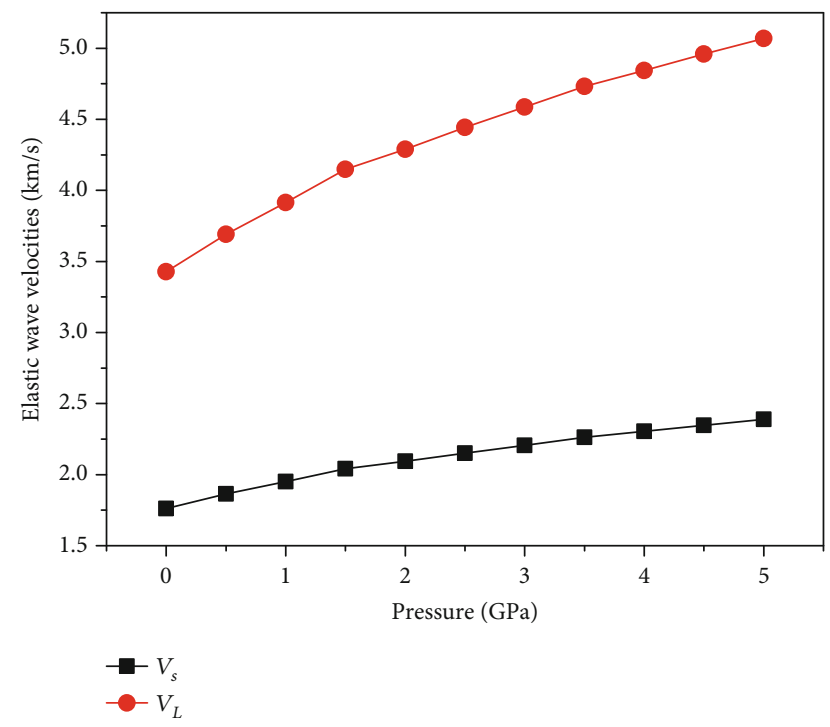

Figure 5: The longitudinal $\left(V_{L}\right)$ and shear wave $\left(V_{S}\right)$ velocities of orpiment $\mathrm{As}_{2} \mathrm{~S}_{3}$ under pressure.

(0 GPa, $1 \mathrm{GPa}, 2 \mathrm{GPa}, 3 \mathrm{GPa}, 4 \mathrm{GPa}$, and $5 \mathrm{GPa})$ are presented. The increasing pressure increases the PDOS peaks of $\mathrm{o}-\mathrm{As}_{2} \mathrm{~S}_{3}$ under the high pressures, and the gap between acoustic and optical modes also shifts to higher frequencies from $350 \mathrm{~cm}^{-1}$ to $500 \mathrm{~cm}^{-1}$.

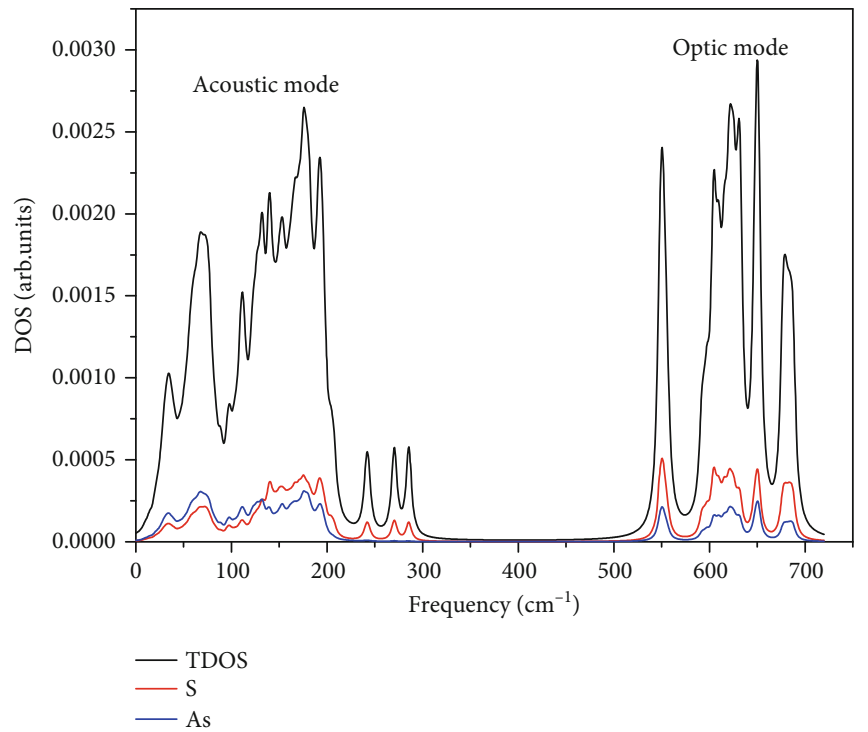

Figure 6: The partial density of states (PDOS) and total phonon density of states (TDOS) of orpiment $\mathrm{As}_{2} \mathrm{~S}_{3}$ at $0 \mathrm{GPa}$ pressure.

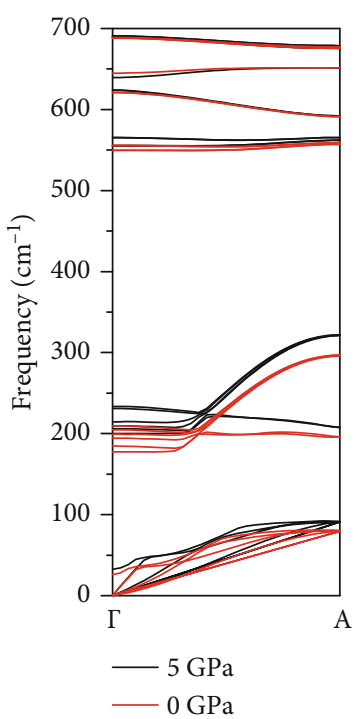

FIgURE 7: The phonon dispersion curve of orpiment $\mathrm{As}_{2} \mathrm{~S}_{3}$ at $0 \mathrm{GPa}$ and $5 \mathrm{GPa}$ pressure.

In summary, the calculated parameters of $\mathrm{o}-\mathrm{As}_{2} \mathrm{~S}_{3}$ in this work are consistent with experiments and those of some published theoretical data. And some of the elastic constants and phonon properties of $\mathrm{o}-\mathrm{As}_{2} \mathrm{~S}_{3}$ at $0 \mathrm{GPa}$ demonstrate fair accordance with the experimental and theoretical data. We 


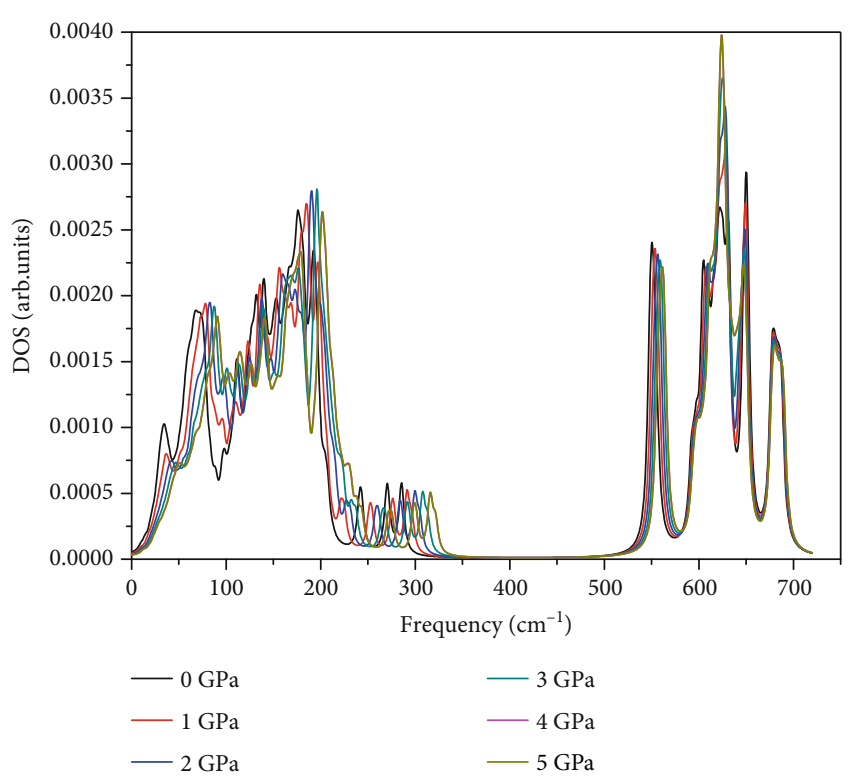

FIgure 8: The total phonon density of states (TDOS) of orpiment $\mathrm{As}_{2} \mathrm{~S}_{3}$ under pressure.

hope that our results add value to the forthcoming researches about $\mathrm{o}-\mathrm{As}_{2} \mathrm{~S}_{3}$ under pressure.

\section{Conclusions}

In this paper, we applied the Dreiding interatomic potential for the geometry optimization on the structural properties of $\mathrm{o}-\mathrm{As}_{2} \mathrm{~S}_{3}$ and studied both the ground state and pressuredependent elastic, mechanical, and phonon dispersions of $\mathrm{o}-\mathrm{As}_{2} \mathrm{~S}_{3}$. The present results for the ground state of o-As $\mathrm{S}_{3}$ were former experiments for the elastic constants, and the phonon characteristics were consistent with the published theoretical data. Moreover, we presented the effect of pressure on $\mathrm{o}-\mathrm{As}_{2} \mathrm{~S}_{3}$ and obtained some reasonable results. The mechanical properties of bulk modulus, shear modulus, Young's modulus, and longitudinal elastic character were increments under pressure. The $\mathrm{o}-\mathrm{As}_{2} \mathrm{~S}_{3}$ exhibits ductile character under high pressure. At last, the increasing pressure increases the PDOS peaks of $\mathrm{o}-\mathrm{As}_{2} \mathrm{~S}_{3}$ under the high pressures, and the gap between acoustic and optical modes also shifts to higher frequencies from $350 \mathrm{~cm}^{-1}$ to $500 \mathrm{~cm}^{-1}$.

\section{Data Availability}

The research data used to support the findings of this study are included in the article.

\section{Conflicts of Interest}

We declare that we have no conflict of interest about the manuscript.

\section{Acknowledgments}

This research was supported by the National Science and Technology Major Project (Grant No. 2017-VI-0012-0084), the Fundamental Research Funds for the Central Universities (Grant No. FRF-GF-19-029B), and the National Natural Science Foundation of China (Grant No. 51471022).

\section{References}

[1] O. Boudrifa, A. Bouhemadou, N. Guechi, S. Bin-Omran, Y. AlDouri, and R. Khenata, "First-principles prediction of the structural, elastic, thermodynamic, electronic and optical properties of $\mathrm{Li}_{4} \mathrm{Sr}_{3} \mathrm{Ge}_{2} \mathrm{~N}_{6}$ quaternary nitride," Journal of alloys and compounds, vol. 618, pp. 84-94, 2015.

[2] D. Duan, X. Huang, F. Tian et al., "Pressure-induced decomposition of solid hydrogen sulfide," Physical Review B, vol. 91, no. 18, article 180502, 2015.

[3] Z. Zeng, C. S. Garoufalis, S. Baskoutas, and G. Bester, "Excitonic optical properties of wurtzite $\mathrm{ZnS}$ quantum dots under pressure," The Journal of Chemical Physics, vol. 142, no. 11, article 114305, 2015.

[4] M. Güler and E. Güler, "Theoretical analysis of elastic, Mechanical and Phonon Properties of Wurtzite Zinc Sulfide under Pressure," Crystals, vol. 7, no. 6, 2017.

[5] V. V. Brazhkin, Y. Katayama, M. V. Kondrin, A. G. Lyapin, and H. Saitoh, "Structural transformation yielding an unusual metallic state in liquid $\mathrm{As}_{2} \mathrm{~S}_{3}$ under high pressure," Physical Review B, vol. 82, no. 14, article 140202, 2010.

[6] G. V. Gibbs, A. F. Wallace, R. Zallen et al., "Bond paths and van der Waals interactions in orpiment, $\mathrm{As}_{2} \mathrm{~S}_{3}$," The Journal of Physical Chemistry. A, vol. 114, no. 23, pp. 6550-6557, 2010.

[7] P. Srivastava, H. Singh Mund, and Y. Sharma, "Investigation of electronic properties of crystalline arsenic chalcogenides: theory and experiment," Physica B: Condensed Matter, vol. 406, no. 15-16, pp. 3083-3088, 2011.

[8] Y. Watanabe, H. Kawazoe, and M. Yamane, "Imperfections in amorphous chalcogenides. III. Interacting-lone-pair model for localized gap states based on a tight-binding energy-band calculation for $\mathrm{As}_{2} \mathrm{~S}_{3}$," Physical Review B, vol. 38, no. 8, pp. 5677$5683,1988$.

[9] D. W. Bullett, "Electronic structure of arsenic chalcogenides," Physical Review B, vol. 14, no. 4, pp. 1683-1692, 1976.

[10] S. G. Bishop and N. J. Shevchik, "Densities of valence states of amorphous and crystalline $\mathrm{As}_{2} \mathrm{~S}_{3}, \mathrm{As}_{2} \mathrm{Se}_{3}$, and $\mathrm{As}_{2} \mathrm{Te}_{3}$ : X-ray photoemission and theory," Physical Review B, vol. 12, no. 4, pp. 1567-1578, 1975.

[11] Y. Sharma and P. Srivastava, "Optical and transport properties and electronic structure of nickel doped arsenic chalcogenides," Computational Materials Science, vol. 53, no. 1, pp. 451-459, 2012.

[12] A. R. Kampf, R. T. Downs, R. M. Housley, R. A. Jenkins, and J. Hyrsl, "Anorpiment, $\mathrm{As}_{2} \mathrm{~S}_{3}$, the triclinic dimorph of orpiment," Mineralogical Magazine, vol. 75, no. 6, pp. 28572867, 2011.

[13] C. Y. Yang, M. A. Paesler, and D. E. Sayers, "Chemical order in the glassy $\mathrm{As}_{\mathrm{x}} \mathrm{S}_{1-\mathrm{x}}$ system: an X-ray-absorption spectroscopy study," Physical Review B, vol. 39, no. 14, pp. 10342-10351, 1989.

[14] E. Soignard, O. B. Tsiok, A. S. Tverjanovich et al., "PressureDriven Chemical Disorder in Glassy $\mathrm{As}_{2} \mathrm{~S}_{3}$ up to $14.7 \mathrm{GPa}$, Postdensification Effects, and Applications in Materials Design," The Journal of Physical Chemistry B, vol. 124, pp. 430-442, 2020. 
[15] C. H. Zhang, S. Huang, J. Shen, and X. N. Chen, "Chen's lattice inversion embedded-atom method for $\mathrm{Ni} \mathrm{Al}$ alloy," Chinese Physics B, vol. 21, no. 11, article 113401, 2012.

[16] C. H. Zhang, S. Huang, J. Shen, and X. N. Chen, "Structural and mechanical properties of $\mathrm{Fe}-\mathrm{Al}$ compounds: an atomistic study by EAM simulation," Intermetallics, vol. 52, pp. 86-91, 2014.

[17] L. C. He, S. S. Guo, J. C. Lei, Z. D. Sha, and Z. S. Liu, "The effect of stone-thrower-Wales defects on mechanical properties of graphene sheets - a molecular dynamics study," Carbon, vol. 75, pp. 124-132, 2014.

[18] C. H. Zhang, Y. Wang, and D. B. Sun, "The molecular dynamics simulation on the mechanical properties of $\mathrm{Ni}$ glass with external pressure," International Journal of Modern Physics $B$, vol. 31, no. 20, article 1750138, 2017.

[19] J. D. Gale and A. L. Rohl, “The General Utility Lattice Program (GULP)," Molecular Simulation, vol. 29, no. 5, pp. 291-341, 2003.

[20] S. L. Mayo, B. D. Olafson, and W. A. Goddard, "DREIDING: a generic force field for molecular simulations," The Journal of Physical Chemistry, vol. 94, no. 26, pp. 8897-8909, 1990.

[21] R. Devanathan, A. Venkatnathan, and M. Dupuis, "Atomistic simulation of nafion membrane: I. Effect of hydration on membrane nanostructure," The Journal of Physical Chemistry. $B$, vol. 111 , no. 28 , pp. 8069-8079, 2007.

[22] P. G. Boyd, S. M. Moosavi, M. Witman, and B. Smit, "Forcefield prediction of materials properties in metal-organic frameworks," Journal of Physical Chemistry Letters, vol. 8, no. 2, pp. 357-363, 2017.

[23] R. Fletcher, "A new approach to variable metric algorithms," The Computer Journal, vol. 13, no. 3, pp. 317-322, 1970.

[24] H. J. Monkhorst and J. D. Pack, "Special points for Brillouinzone integrations," Physical Review B, vol. 13, no. 12, pp. 5188-5192, 1976.

[25] D. J. E. Mullen and W. Nowacki, "Refinement of the crystal structures of realgar, AsS and orpiment, $\mathrm{As}_{2} \mathrm{~S}_{3}$," Zeitschrift für Kristallographie - Crystalline Materials, vol. 136, no. 1-2, pp. 48-65, 1972.

[26] W. Voigt, Lehrbuch der Kristallphysik (mit Ausschluss der Kristalloptik), Vieweg+Teubner Verlag, 1928.

[27] A. Reuss, "Berechnung der Fließgrenze von Mischkristallen auf Grund der Plastizitätsbedingung für Einkristalle," ZAMM-Journal of Applied Mathematics and Mechanics/Zeitschrift für Angewandte Mathematik und Mechanik, vol. 9, no. 1, pp. 49-58, 1929.

[28] S. Hirsekorn, "Elastic properties of polycrystals: a review," Textures and Microstructures, vol. 12, no. 1-3, pp. 1-14, 1990.

[29] R. L. Fleischer, "Substitutional solutes in AlRu-I. Effects of solute on moduli, lattice parameters and vacancy production," Acta Metallurgica et Materialia, vol. 41, no. 3, pp. 863-869, 1993.

[30] L. E. McNeil and M. H. Grimsditch, "Elastic constants of $\mathrm{As}_{2} \mathrm{~S}_{3}$," Physical Review B, vol. 44, no. 9, pp. 4174-4177, 1991.

[31] S. F. Pugh, "XCII. Relations between the elastic moduli and the plastic properties of polycrystalline pure metals," Philosophical Magazine, vol. 45, no. 367, pp. 823-843, 1954.

[32] B. G. Dick and A. W. Overhauser, "Theory of the dielectric constants of alkali halide crystals," Physics Review, vol. 112, no. 1, pp. 90-103, 1958.
[33] S. Radescu, A. Mujica, P. R. Hernandez et al., "Study of the orpiment and anorpiment phases of As2S3under pressure," Journal of Physics: Conference Series, vol. 950, article 042018, no. 4, 2017.

[34] R. Hill, "The elastic behaviour of a crystalline aggregate," Proceedings of the Physical Society. Section A, vol. 65, no. 5, pp. 349-354, 1952. 